\title{
Control of sustainable management according to multilevel combinatorics of homeostatic mechanisms
}

\author{
Victoriia Mykytenko ${ }^{1, *}$ and Nataliia Sheludko ${ }^{2}$ \\ ${ }^{1}$ Public Institution "Institute of Environmental Economics and Sustainable Development of the National \\ Academy of Sciences of Ukraine", Department of Sustainable Development Methodology, 60, Tarasa \\ Shevchenka Boulevard, 01032, Kyiv, Ukraine \\ ${ }^{2}$ Public institution "Institute for Economics and Forecasting of the National Academy of Sciences of \\ Ukraine", Department of Monetary and Credit Relations, 26, Panasa Myrnoho St., 01011, Kyiv, \\ Ukraine
}

\begin{abstract}
The article aims to develop the methodological base for study and substantiation of homeostatic mechanisms of control of stability of managing systems in the conditions which is implemented according to the sustainable management concept. The article describes features of main types of homeostasis of managing systems (evolutionary, structural, resistant, system homeostasis), their hierarchical closed interrelation and inherent specific and predictive administrative properties. The following is herein substantiated: conditions of homeostasis generation and realization of specific effect of mechanisms and, respectively, regulators of adaptation of managing systems to external and internal transformations; directions and methods to form resistant, to institutional and resource restrictions, complementary managing complexes. The article states that the combinatorics of homeostasis controls includes stabilizing, inertial, adaptation, organizational and economic, kinematic, cybernetic, alarm, cognitive information, reparative, regenerative and other types of controls. It emphasizes that the complex of mechanisms to ensure self-regulating properties of systems must be focused on support of their adaptation abilities to external and internal transformations. Taking into account four-level structural hierarchy of homeostatic properties, the article substantiates the possibility of ensuring adequate design of regulators for their consolidation according to priority objects of tools and events localization.
\end{abstract}

\section{Introduction}

The term "new normal" [1] has been increasingly used to describe the post-crisis (20082009) stage of world economy development characterized by the stagnatory nature of recovery of developed economies from the Great Recession. Growth of uncertainty concerning orientation of further world economic development, instability of evolutionary

\footnotetext{
*Corresponding author: vmikitenko@ukr.net
} 
trajectories, high volatility and turbulence in goods and money markets, declining efficiency of well-established macro-stabilization policy methods have not only deepened the existing deformations but, actually, established the "new norms" [2] which in essence are powerful challenges to the sustainable management concept, not only globally but also at the regional and local levels. First of all, it relates to formation of a large-scale debt overhang in economically developed countries; difficulty of system transformations and impossibility to implement traditional macroeconomic recovery and institutionally focused development models. In such situation, problems of ensuring managing systems stability are mostly caused by the two factors: homeostasis of the internal environment and macroeconomic processes related to global trend dynamics.

The nature of modern transformations is essentially determined by the set of trends concerning updating of management and organization of a spatial vital activity system, natural resource assets and medical and social technologies. In the modern world characterized by rapid changes in technologies, communication means, behavioural norms, priorities, critical environmental and natural resource challenges, there is an objective need to update understanding of the sustainable development category where the issue of ensuring managing systems stability is determining.

Scientific support of implementation of the sustainable management concept needs improvement of methodological approaches concerning estimation of the environment and its reformatting taking into account the "new normal", scope of social, political, environmental, financial and economic hazards and risks that are characterized by extremely complex relations between managing entities, manufacturers, state formations etc. As the latter become more complicated because of transformation of values, the limited natural resource potential, active introduction of various technological innovations, etc., there is a need to update approaches to control over managing systems, ensuring their stability. Thus, the authors focus on substantiation and implementation of the sustainable management concept in the "new normal" conditions based on determination of dominants of ensuring system homeostasis.

\section{Analysis of previous studies and publications}

The scientific and applied work previously done concerning sustainable management is rather limited as regards understanding and comprehension of the "new normal". The "new norms" that appeared and have accompanied development of the world economic system require updating of theoretic methodological bases of practical use of the improved administrative framework that will allow to reach stability and balance of functioning of managing formations. The authors base the hypothesis of ensuring sustainable management in the "new normal" conditions on peculiarities of manifestation of homeostasis in bionatural systems in critical conditions taking into account affinity of social and economic and bio-natural systems.

These complex systems correspond among themselves in strive to stabilization and life cycle extension; reaction to external and internal challenges and shifts. Nevertheless, bionatural systems are studied in greater depth, in particular, as to ensuring homeostasis, typification of its types and mechanisms, etc. Initial methodological bases of the stated and presented concept of ensuring sustainable management according to dominants of homeostasis are theoretic methodological developments of: I. Ponkin (on generation of homeostatic features within the state control system) [3]; A. Takhtadzhian (on individuality of effects of transformation mechanisms of biological and social systems influenced by external and internal destructive factors) [4]; V. Khlebovych (on advantages of regulation of various nature of processes within complex systems near their critical points as manifestation of the principle of minimum action) [5]; medical and biological groundwork presented in the 
works of O. Babaiev, H. Vinberg, M. Hiliarov, H. Zavarzin [6]; applied developments of Trong Hung Dinh, Trung Hieu Dinh and Uwe Götze [7] on determination of stability criteria and use of the method for assessing life cycle stability taking into account economic, environmental and social factors of sustainable development.

Considering the results of previous methodological and applied achievements, authors of the article aim to substantiate and develop the complex methodological base for study of homeostatic mechanisms of ensuring managing systems stability in the "new normal" conditions according to the sustainable management concept.

\section{Results and discussion}

Based on the generalized theoretical foundation of homeostasis [3-6], we singled out the following types thereof taking into account certain restrictions of the external and internal environment of managing systems functioning (Fig. 1): genetic homeostasis (this type of homeostasis is evolutionary); structural homeostasis; immunological homeostasis (or resistant homeostasis which is identified taking into account the determining features and possible response of a system to risks and hazards of various nature); system homeostasis reflecting multidimensional stability of the internal environment of managing systems functioning. The identified homeostasis types are interrelated and have the relevant level of complexity. They interact in such a way that each type of homeostasis must be generated and based taking into account self-reproducing ability of managing systems in the conditions of previously formed homeostasis (taking into account the hereditary factor). Determining the essence of homeostasis as stability of the internal environment of a complex system and as a condition of its independent existence, it is expedient to ensure its regulation as regards implementation of targets in three directions:

a) determining thoroughness of homeostatic mechanisms for each type and level of homeostasis;

b) creating conditions to ensure the inverse relationship within a dynamic selfregulating system and its adaptation to external transformations;

c) offering factors of ensuring self-regeneration of managing formations at critical shifts of the internal and external environment that can be used for each of four types of homeostasis.

Acknowledging immediacy of resolution of problems related to ensuring sustainable management, we should apply a new way to look at the factor of homeostasis dominants application. In the context of further development of views to homeostasis concept and considering etymology of the word (Latin homeostasis $<$ Greek homoios - identical, similar + stasis - state), dominants of achievement of relative dynamic sustainability of the internal environment of managing systems should be determined in the following areas:

a) application of system approach aspects to ensuring all five [8] resource and functional determinants of sustainable management (natural resource, production, societal, environmental and economic processes);

b) formation of a complex system of adaptation mechanisms (coordinated by the state, regional and local administration systems) aimed to eliminate or restrict the effects of various destructive factors on the systems.

The latter allow managing systems, despite changes in the outer world and shifts occurring in the course of transformation of sustainable management determinants, to maintain sustainability of the structure of natural resource, production, societal, environmental and economic processes and specific properties of the internal functioning environment.

According to basic ideas of homeostasis, a normal state is characterized by narrow homeostatic borders of fluctuation of economic, environmental, natural resource, societal 
and production components, and amplitude of those fluctuations is determined by certain features of the external and internal environment (and is unequal for different territorial managing systems).

IV. SYSTEM HOMEOSTASIS: dynamic sustainability of the internal environment of an economic system. It is formed by different types of stability, even at cardinal shifts in the internal environment and critical effects of the external environment. Ensures: effectiveness of economic and management activity, elimination of turbulence in the course of five processes that are basic for sustainable management, ensures the corresponding dimensions of concentration, environmental compatibility and technological efficiency of production, etc.

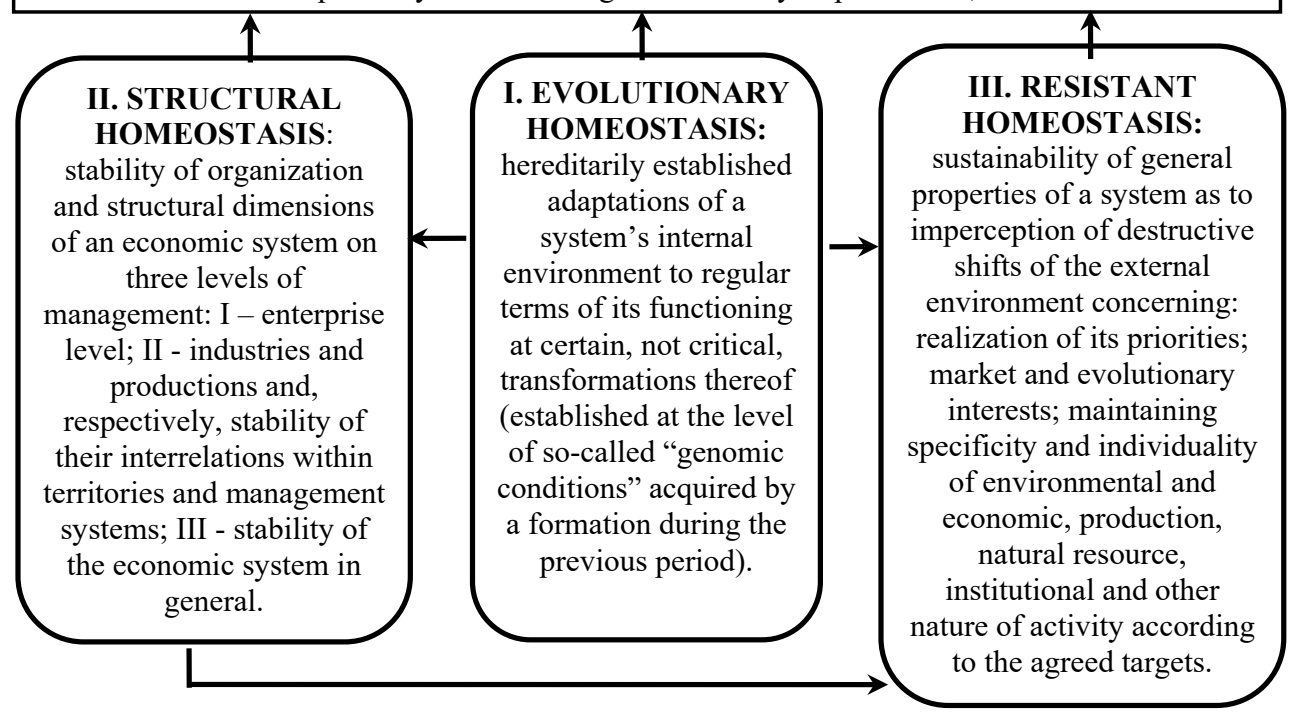

Fig. 1. Types of homeostasis of managing systems and hierarchical levels of complexity of their generation.

Based on this, the relevant complexes of homeostasis ensuring mechanisms are also formed. And effectiveness of use of multilevel combinatorics of homeostatic mechanisms and, respectively, their complexity mostly depends on the level of evolutionary development of a managing system, its industry and technological structure of production and economic activity, space coordinates of territories, scale of strategic potential and volumes of natural resource assets etc. At the same time, the combinatoric structure of the complex of self-regulating mechanisms for each type of homeostasis (Fig. 1) is formed following achievement of a number of targets, including: a) forming the general system for control over ensuring stability of matrix type managing systems; b) creation of the congruent institutional environment at each stage of achievement of homeostasis within managing systems; c) overcoming the existing institutional restrictions within state formations, elimination of hazards and risks of sustainable development.

Along with that, multistage homeostatic mechanisms are formed taking into account general directions of evolution of managing formations in the "new normal" conditions and are primarily focused on: improvement of alarm resonance of homeostatic means in use to challenges and hazards; further strengthening of homeostatic response following the five processes that are basic for sustainable development (economic, environmental, production, natural resource, societal processes). 
Table 1. Basic methodological provisions of formation of ability of managing systems to ensure evolutionary, structural, resistant and system homeostasis.

\begin{tabular}{|c|c|c|c|}
\hline \multicolumn{4}{|c|}{ Generation of ability to ensure } \\
\hline evolutionary & structural & \begin{tabular}{|l|} 
resistant homeostasis \\
\end{tabular} & system homeostasis \\
\hline $\begin{array}{l}\text { - participants of } \\
\text { five types } \text { of } \\
\text { relations, basic for } \\
\text { sustainable } \\
\text { development, to } \\
\text { adapt to unstable } \\
\text { spatial, social and } \\
\text { political, market, } \\
\text { technological and } \\
\text { social factors. }\end{array}$ & $\begin{array}{l}- \\
\text { orderliness } \\
\text { of the } \\
\text { relations } \\
\text { system; }\end{array}$ & $\begin{array}{l}\text { - necessary and sufficient } \\
\text { degree of resistance of } \\
\text { control systems to influence } \\
\text { of negative factors; resilience } \\
\text { (ability to return to basic } \\
\text { parameters and initial mode } \\
\text { after violations); stability (a } \\
\text { "stable" object maintains } \\
\text { stability for a certain time); } \\
\text { survivability; }\end{array}$ & $\begin{array}{l}\text { - subjects of control of five basic } \\
\text { processes to employ the "minimum } \\
\text { action factor" (factor of } \\
\text { minimization and simplification). } \\
\text { The state and regional control does } \\
\text { not seek to put more effort into } \\
\text { activity than is required for } \\
\text { implementation and maintenance } \\
\text { of a certain sustainable } \\
\text { development. }\end{array}$ \\
\hline $\begin{array}{lr} & \text { when } \\
\text { implementing new } \\
\text { projects, to adapt to } \\
\text { instability r of } \\
\text { competition factors, } \\
\text { innovation and } \\
\text { technology factors, } \\
\text { limited assets, } \\
\text { social instability; }\end{array}$ & $\begin{array}{l}\text { - openness } \\
\text { of the } \\
\text { relations } \\
\text { system; }\end{array}$ & 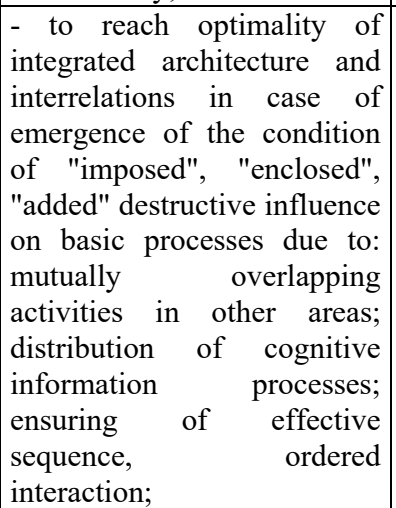 & $\begin{array}{l}\text { - state control systems to create } \\
\text { network of powerful cognitive } \\
\text { information subsystems that will } \\
\text { structurally imitate and design } \\
\text { actions of the key system and its } \\
\text { elements. As a result of creation } \\
\text { and use of information network, } \\
\text { subjects of control will have the } \\
\text { extensive range of options of } \\
\text { administrative tools expedient for } \\
\text { use in a particular time and under } \\
\text { particular circumstances depending } \\
\text { on the goal; }\end{array}$ \\
\hline $\begin{array}{l}- \text { - interaction of the } \\
\text { controlling and the } \\
\text { controlled sub- } \\
\text { system according to } \\
\text { the strategy; } \\
\text { sustainability and } \\
\text { adaptation to } \\
\text { changes } \\
\text { economic, } \\
\text { resource, } \\
\text { institutional, } \\
\text { environmental } \\
\text { factors, having } \\
\text { gained socially } \\
\text { effect; }\end{array}$ & $\begin{array}{l}\text { - quality of } \\
\text { the control } \\
\text { system; }\end{array}$ & $\begin{array}{l}\text { necessary (sufficient) } \\
\text { degree of stability of a } \\
\text { managing system and control } \\
\text { systems to the impact of } \\
\text { negative factors. It means not } \\
\text { only their ability to prevent } \\
\text { essential } 4 \text { difficulties } \\
\text { ("distress"), but also to } \\
\text { endure them with the least } \\
\text { possible losses for a } \\
\text { formation, system, or the } \\
\text { state in general. }\end{array}$ & $\begin{array}{l}\text { - to provide homeostasis of a } \\
\text { managing system as a real and/or } \\
\text { expressive condition that reflects } \\
\text { the optimal properties: negentropy } \\
\text { (to support the set degree of a } \\
\text { certain disorder/entropy); stability } \\
\text { (maintenance of coherence of } \\
\text { internal state and measurement of } \\
\text { adaptability to changes in the } \\
\text { external anvironment); } \\
\text { conservatism and balance (to } \\
\text { restore balance in a managing } \\
\text { system); stability implemented in } \\
\text { the determined parameters in any } \\
\text { case scenario; }\end{array}$ \\
\hline $\begin{array}{l}- \text { stability of } \\
\text { managing systems, } \\
\text { by implementing } \\
\text { the strategy of } \\
\text { control of socially } \\
\text { oriented } \\
\text { development, to } \\
\text { adapt to market } \\
\text { instability factors. }\end{array}$ & $\begin{array}{l}\text { - strategic } \\
\text { sustainabili } \\
\text { ty of the } \\
\text { relations } \\
\text { system; }\end{array}$ & $\begin{array}{l}\text { - to implement full-scale } \\
\text { control ability; to create and } \\
\text { apply a necessary and } \\
\text { sufficient measure of } \\
\text { negentropic potential of a } \\
\text { control system for } \\
\text { homeostasis; to reach a } \\
\text { stabilization condition of a } \\
\text { system according to five } \\
\text { specific } \\
\text { characteristics. }\end{array}$ & $\begin{array}{l}\text { - control systems to development } \\
\text { and acceptance of: new social and } \\
\text { economic programs; relevant type } \\
\text { of mechanisms and implementation } \\
\text { of target events aimed at their } \\
\text { implementation and maintenance; } \\
\text { tendencies to support } \\
\text { implementation of the existing } \\
\text { program, despite "forced" } \\
\text { corrections and intervention in the } \\
\text { current state of affairs of "strategic } \\
\text { partners". }\end{array}$ \\
\hline
\end{tabular}

Source: substantiated and systematized by the authors based on [9-12]. 
In the course of individual development of a particular system (during each stage of its life cycle) and with permanent improvement of control functionalities within the system, homeostatic responses will also undergo evolutionary changes.

For ensuring homeostasis of managing systems, it is particularly essential to ensure sustainability of the financial dominant distinguished by the most active response to changes but also by lesser resistance to transformations in the internal and external environment. It should be noted that there are the relevant difficulties in analyzing interrelation between manifestations and potential accompanying changes of the financial dominant of sustainable homeostasis due to inconsistency of the currently distorted functional component of the state system for sustainable development control [9].

In view of the four-level format of homeostasis of managing systems (formations), we point out several basic provisions of improving efficiency of control over ensuring their stability by orientation of state, regional and local management systems to compliance with basic norms of economic, natural resource, production, environmental and societal elements (Table 1). This position acquires particular significance for disclosure of stages and selection of the relevant set of steps for improvement of the modern state control system and national financial systems in the context of ensuring sustainable management in the new conditions of hyper-financialization of the world economy $[2 ; 10 ; 11]$ and the global structural, environmental, medical and social crisis.

From the point of view of homeostatic approach, stability and balance connects with design to use compensation mechanisms and methods of adequate response to any case scenarios. Respectively, it is possible to apply "artificial intelligent control systems" that are most expedient and efficient to use in system homeostasis models. The modern system of state control over sustainable management processes (in the context of ensuring stability of managing systems) has to gain ability to create a network of powerful cognitive information subsystems which, in the test mode, will structurally imitate and design actions of the key system that, as a rule, has big inertia in the course of performance of most of its administrative functions. I.e., interested managing entities will have the range of options of administrative tools expedient for use depending on the goal and, respectively, developed economic development programs [13-15].

However, system homeostasis can be, to some extent, limited when multidimensional forms of course of processes (of various nature, as initiation of turbulence within them is predictable [9]) existing within a certain managing system can initiate negative feedback that will slow down processes of adaptation of newly created institutional rules to the "new normal" and goal-oriented behavior of the main actors. Thus, the above stated will also prevent the managing system from constantly changing and adapting to variable circumstances, while keeping its main form and characteristics. At the same time, the internal balance will not be breached by cardinal goal-oriented activity of entities, even when change of the external environment exceeds internal adaptation transformations that have facilitated its phase transition to the new, more robust, format of stable balance. However, ensuring such stabilization conditions is possible only in case of generation of homeostatic properties within managing formations on all four complexity levels (evolutionary, structural, resistant, system level) [16-17].

Hence, we conclude: the concept of control over ensuring stability of managing systems (according to constitutive and key rules and dominants of homeostasis) that is created to achieve sustainable management, should help build such dynamic formations which, under any operation conditions, will gain specific homeostatic features (even in case of turbulent shifts in the internal and external environment), but only if they consecutively pass four stages of system generation of these properties. This will obligatorily held to achieve and ensure stabilization of activity of territorial entities and, respectively, their sustainable management within the state (Table 2 - grouping of homeostatic properties of management 
systems by less complex first and second levels of management of sustainable management and Table 3 - by the third and fourth levels of complex control to ensure sustainable management).

Table 2. Grouping of homeostatic properties of control systems by the first two levels of complexity of control over the provision of sustainable management.

\section{Homeostatic properties of managing systems by levels of control of their homeostasis} Evolutionary homeostasis - properties of the 1st level of control complexity

1.1) adaptation - use of hereditarily established adaptation mechanisms of a managing system to its regular functioning conditions in case of certain (not critical) transformations of the external environment (at the level of "genomic operating conditions" of a system according to: industry structure, social and economic parameters of development, scope of the strategic potential, efficiency of use of assets, energy efficiency of industrial production, etc.);

1.2) stabilization - ensuring evolutionary stability of functioning of a system that may change throughout certain time with minimum deviation of dynamic parameters (increase/decrease) from the established level;

1.3) stabilization - ensuring uniformity of a system functioning (in economic and production areas) with established stabilization parameters (Self-alignment, Inertia, Delay, industry structure of formations and subsystems) in the absence of cardinal shifts in the external environment;

1.4) adaptation - ensuring closeness of chains of control over economic and production processes of a system at continuous severization of requirements to effectiveness in case of non-critical changes in the external environment;

1.5) inertial - to maintain certain conservatism and inertia of economic and production processes, ability to correct violations through their reparation (regeneration) using blocking administrative tools, localization of efforts to eliminate recessive deviations for certain objects;

\section{Structural homeostasis - properties of the $2^{\text {nd }}$ level of control complexity}

2.1) stabilization - to provide stability of a system's organizational structure (according to three hierarchical levels) using mechanisms of alignment of dynamics of: enterprises, managing entities and their components; industries and productions, stability of their interrelations within certain territories and control systems; managing system, in general;

2.2) stabilization - ensuring self-alignment, adaptation and self-regulation of activity within production and managing systems and a managing system (formation) at local shifts in the external environment;

2.3) adaptation - to provide adaptation of logistic structures of a system to individual shifts in the external environment following reception (assimilation) and transfer of societal, system and universal and institutional, spatial and technological forms and administrative methods to improve efficiency of use of assets, regulation and correction of structural, production and social and economic parameters of stabilization and sustainable development;

2.4) alarm - to ensure object and target orientation of activities for control of: a) urgency of adequate response to the shift both in the systems internal and external environment; b) positive inverse relationship when the lowest level homeostasis becomes a basis for ensuring sustainability of structures of higher level and efficiency;

2.5) reparative - regulation of structural homeostasis by reparative regeneration through complete (creation/ introduction) or partial replacement of an inefficient managing entity in the production or consumption chain with another managing entity. Is ensured through: use of new technology; functioning in other field of activity or public practice; development of a new type of public relations not used before (information, global tetc.);

Actually, considering the list of specific properties of managing systems substantiated and formulated in Table 2 and Table 3, which are differentiated according to four (complexity) levels of control of ensuring their homeostasis, it is possible to visualize the relevant closed structural logic diagram of formalization of interdependence of special features according to evolutionary, structural and resistant type of homeostasis which will ensure generation of system conditions during functioning of territorial entities, even, in turbulent metamorphoses, achievement of system homeostasis thereby. 
Table 3. Grouping of homeostatic properties of control systems by the third and fourth levels of complexity of control over the provision of sustainable management.

\section{Homeostatic properties of managing systems by levels of control of their homeostasis Resistant homeostasis - properties of the $3^{\text {rd }}$ level of control complexity}

3.1) specific administrative - preservation of: forms of control and regulation characterized by unity of rationality and logicality of effect of control schemes and mechanisms; individuality of economic, production, environmental, natural resource, institutional, social and other of activity of a formation; 3.2) predictive administrative - to support a certain level of economic, environmental, technological, social, cultural and other type of safety due to practical application of closed predictive control schemes;

3.3) cognitive information - to development of a system according to directions and goals coordinated with all managing entities and with territorial community taking into account: scope of the strategic potential; opportunities of its rational development and expansion; existing and potential hazards and risks;

3.4) stabilization - to sustainability of a system's general features concerning imperceptibility to: destructive shifts in the external environment during implementation of priorities, market and evolutionary interests; coercive administrative actions of political elites to eliminate the "state of imperfection"; transforming influence of foreign cultural environment on development of information industry, reflection of reality in the consciousness of managing entities;

3.5) reparative - formation, constant updating and improvement and simultaneous full-scale implementation of two types of self-regulating homeostatic mechanisms corresponding to binary levels of resistance as rlegards the existing, implicitly interconnected, elements: a managing system and a control system;

3.6) regenerative - consideration and rectification and subsequent reconstruction of a system at different life cycle stages, taking into account peculiarities of forming interrelations and interdependence depending on complexity and hierarchy of its elements, directions and objects for exchange of technologies and use of controls;

3.7) binary - objective: estimation and acknowledgement of measurements of effectiveness of using "protective" mechanisms; determination of the: spatial scope of a system; technological level and versatility of productions; cognitive information level of networks and staffing;

3.8) predictive administrative - on severization of requirements to: managing entities, their qualification, professionalism and responsibility which, in non-compliance conditions, destroys the control system and stabilization in case of: accumulation in the internal environment of risks of economic, environmental, natural resource and production activity; violations on both levels (management and control) of resistant homeostasis; shortening of the life cycle and inefficiency of homeostatic regulation; loss of logistic and information communications; "failure" of adaptation mechanisms of separate elements, etc.;

\section{System homeostasis - properties of the $4^{\text {th }}$ the level of control complexity}

4.1) stabilization - ensuring measurements of sustainability of the internal environment of a managing system according to which generation of different types of stability at cardinal shifts and critical effects of the external environment takes place;

4.2) organizational and economic - ensuring effectiveness of economic and administrative activity; elimination of turbulence in the course of basic processes; ensuring proper and sufficient measurements of concentration and technological effectiveness;

4.3) kinematic - mitigation of susceptibility of a system to changes in its internal and external environment at any time in the course of basic, for sustainable development, processes that is more susceptible than a control system;

4.4) cybernetic - constant improvement of control systems to level destructive (external, internal) effects using the cybernetic principle of regulation (when, within a system, a perfect control unit and its working part are created that will adequately respond to the regulating influence of the control unit);

4.5) alarm - implementation of controls according to the negative feedback principle by ensuring extra close interaction of the established administrative and humoral mechanisms through additional introduction (incorporation) into the system of sufficient (determined) volume of resources or attraction and development of a certain type of reserves. 
Maintenance of closeness in elements of implementation of effect of interdependence and interrelations between homeostatic properties of systems (territorial natural and managing formations, objects, elements, industries, productions, etc.) is presented in Fig. 2.

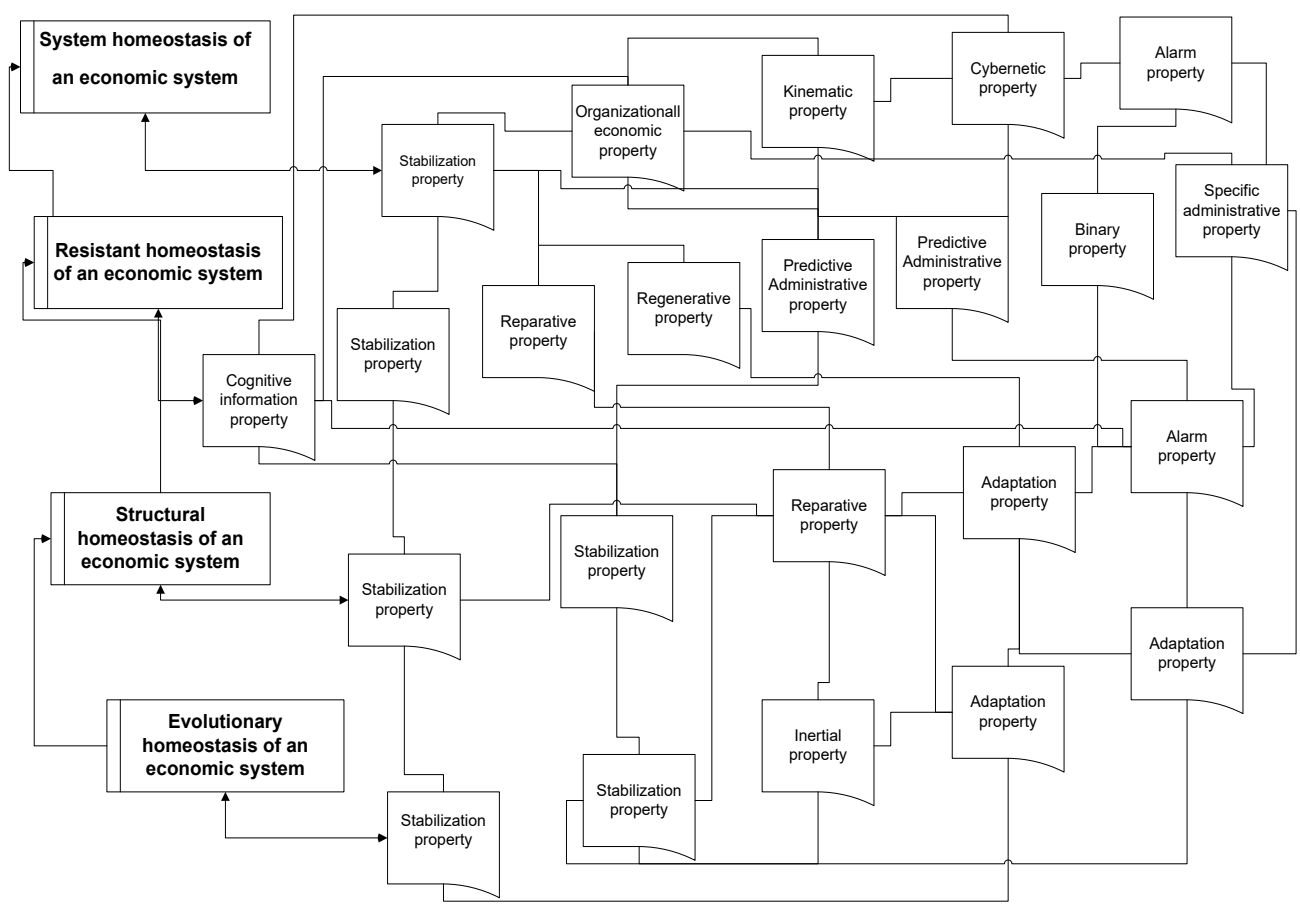

Fig. 2. Structural logic diagram of closed inverse relationship and interdependence between homeostatic properties of managing systems.

The above stated will also ensure, according to closeness of the control scheme, stabilization of activity within their limits and effectiveness of functioning, however, only under conditions of formation of the stability control matrix system format of which will be adequate to the "new normal" world economic dynamics.

Summing up the above, we should state that we have developed the complex methodological base for study and development of homeostatic mechanisms of ensuring stability of managing systems (along with development of conceptual and categorical framework of the sustainable management theory), using which we singled out, structured and identified four types of managing formations homeostasis (evolutionary, structural, resistant, system homeostasis).

The above and substantiated allowed the authors to establish and prove the adequacy of the world economic dynamics in relation to: a) hierarchical closed interrelation and interdependence of four subsystems of control over homeostasis of managing systems; $b$ ) stabilization, inertial, adaptation, organizational and economic, kinematic, cybernetic, alarm, cognitive information, reparative, regenerative, binary, specific and predictive administrative properties of managing systems which the latter must possess in order to achieve homeostasis of a certain type; c) homeostatic mechanisms of ensuring inverse relationship within the self-regulating managing system and its adaptation to external and internal transformations in order to achieve sustainable management within any state formation. 
The latter also became the basis for creation of the original scheme of closed interrelation and interdependence between the four-level hierarchy of homeostatic properties of managing systems which ensures design and development of the relevant type of regulators and their consolidation according to priority objects following territorial formations acquiring system features by degrees of evolutionary, structural, resistant and system homeostasis.

\section{Conclusions}

Improvement of scientific and applied tools of ensuring sustainable management in the "new normal" conditions requires updating of the methodological base that must be based on use of homeostatic mechanisms of stability of managing formations. In this regard, the authors offer four types of homeostasis (evolutionary, structural, resistant and system homeostasis) and note that the complex nature of homeostasis requires taking into account problems of hierarchy of a system's structural components and their interrelations and interdependence, development of which significantly impacts the choice of administrative leverage and their use.

Combinatorics of homeostasis controls must be sufficiently developed and must include stabilization, inertial, adaptation, organizational and economic, kinematic, cybernetic, alarm, cognitive information, reparative, regenerative and other types of controls. At the same time, the complex of homeostatic mechanisms of ensuring self-regulating properties of managing systems must be focused on support of their adaptation abilities to external and internal transformations in order to achieve sustainable management targets in the turbulent world economic system. Only considering the four-level structural hierarchy of homeostatic properties of managing systems, it is possible to ensure designing and consolidation of regulators that are adequate to the real process according to priority objects of efforts exertion.

The perspective directions of further research in the field of ensuring sustainable management are, first of all, issues of formation of the general control system to ensure stability of matrix type managing systems; creation of the congruent institutional environment at each stage of achievement of homeostasis of territorial managing systems; overcoming the existing institutional restrictions, elimination of hazards and risks to sustainable development, with their differentiation by spatial features.

This work was carried out in the framework of the project III-34-20 "Methodological principles of sustainable management" (State registration № 0120U100187).

\section{References}

1. El-Erian, M. (2010). Navigating the New Normal in Industrial Countries. Washington, Per Jacobsson Foundation Lecture. http://www.imf.org/external/np/speeches/2010/101010.htm

2. Vishnevsky, V., \& Shelud'ko, N. (2017). World monetary centres at the stage of global financial instability: risks, challenges and perspectives. Economy of Industry, 4, 75-96. http://dspace.nbuv.gov.ua/handle/123456789/127378

3. Ponkin, I. V. (2018). Homeostasis of the public administration system. Public service, 3, 18-22. https://pa-journal.igsu.ru/articles/6124

4. Takhtadzhyan, A. L (2001). Principia tektologika. Principles of organization and transformation of complex systems: evolutionary approach St. Petersburg: SPHFA Publishing House. https://www.twirpx.com/file/2009524 
5. Khlebovich, V. V. (2007). Levels of homeostasis. Nature, 2, 61-66. http://vivovoco.ibmh.msk.su/vv/journal/nature/02 07/hom.htm

6. Gilyarov, M. S., Babaev, A. A., Vinberg G. G., Zavarzin, G. A. \& Yablokov, A. V. et al. (1986). Biological encyclopedic dictionary (2nd ed.). Moscow: Soviet Encyclopedia Publishing House.

7. Trong, Hung Dinh, Trung, Hieu Dinh, \& Uwe, Götze (2020). Integration of Sustainability Criteria and Life Cycle Sustainability Assessment Method into Construction Material Selection in Developing Countries: The Case of Vietnam. International journal for sustainable development and planning, 15 (8), 1145-1156. https://doi.org/10.18280/ijsdp.150801

8. Shkarlet, S. M. \& Mykytenko, V. V. (2020). Transformation of ideas about sustainable management: opportunities for scientific and technological development. Science and science, 4 (110), 6-24. https://doi.org/10.15407/sofs2020.04.006

9. Krejdych, I. M., Litsur, I. M., Khudolej, V. Yu. \& Shkarlet, S. M. et al. (2019). Independent Ukraine in the coordinates of sustainable development (2nd ed.). Chernihiv: Chernihiv National Technological University.

10. Belarus, O. G. (2014). Global structural crisis and transformations of the financial world system. Finance of Ukraine, 4, 32-45. http://nbuv.gov.ua/UJRN/Fu_2014_4_4

11. Belarus, O. G. (2014). Hyperfinancialization of the world economy and its global problems and consequences. Finance of Ukraine, 12, 32-41. http://nbuv.gov.ua/UJRN/Fu $2014 \quad 10 \_4$

12. Shvets, V. I. \& Shostachuk, V. M. (2007). Actuators, regulators and devices. Zhytomyr: Zhytomyr State University "Zhytomyr Polytechnic". http://library.ztu.edu.ua/doccard.php/55963

13. Hutsaliuk, O., Koval, V., Tsimoshynska, O., Koval, M., Skyba, H. (2020). Risk Management of Forming Enterprises Integration Corporate Strategy. TEM Journal, 9(4), 1514-1523.

14. Arsawan, I.W.E., Koval, V., Rajiani, I., Rustiarini, N.W., Supartha, W.G. and Suryantini, N.P.S. (2020). Leveraging knowledge sharing and innovation culture into SMEs sustainable competitive advantage. International Journal of Productivity and Performance Management, (in press).

15. Mikhno, I., Koval, V., Shvets, G., Garmatiuk, O., \& Tamošiūnienė, R. (2021). Green Economy in Sustainable Development and Improvement of Resource Efficiency. Central European Business Review, 10, 1-15.

16. Koval, V., Mikhno, I., Trokhymets, O., Kustrich, L., Vdovenko, N. (2020). Modeling the interaction between environment and the economy considering the impact on ecosystem. E3S Web Conferences, 166, 13002.

17. Glibert, P. M. (2012). Ecological stoichiometry and its implications for aquatic ecosystem sustainability. Current Opinion in Environmental Sustainability, 4(3), 272277. 